\title{
Erratum to: Multifocal electroretinogram responses in Nepalese diabetic patients without retinopathy
}

Prakash Adhikari · Subash Marasini •

Raman Prasad Sah $\cdot$ Sagun Narayan Joshi •

Jeevan Kumar Shrestha

Published online: 21 June 2014

(C) Springer-Verlag Berlin Heidelberg 2014

\section{Erratum to: Doc Ophthalmol \\ DOI 10.1007/s10633-014-9447-9}

In the original publication of the article, third author's name was misspelt. The correct name is given in this erratum.

The online version of the original article can be found under doi:10.1007/s10633-014-9447-9.

P. Adhikari $(\bowtie)$

Visual Science and Medical Retina Laboratories, Institute of Health and Biomedical Innovation, School of

Optometry and Vision Science, Queensland University of Technology, 60 Musk Avenue, Kelvin Grove, Brisbane, QLD 4059, Australia

e-mail: p.adhikari@qut.edu.au

S. Marasini

Ajou University Neuroscience Postgraduate Program, Suwon, South Korea

R. P. Sah · S. N. Joshi · J. K. Shrestha

Eye Department, Institute of Medicine, Tribhuvan

University, Kathmandu, Nepal 